Notwithstanding vigorous medical treatment, he doubtful utility to the hearing, are of some, though grew worse and began to lose flesh, and suffer great slight, danger to life. These are the operations for pain. I wrote and suggested that he go to some hos- the removal of one or more of the ossicles with or pital, where he could have the best advantages. He without part or all of the drum membrane, and mobilthen went to New York, consulted a well known sur- ization of the stapes. These procedures, as much geon, who had sections of the tumor made for micro- recorded (and perhaps much more unrecorded) expescopic examination. It was decided to be a fibroma rience goes to show, are often followed, even when and non-malignant. The surgeon removed the growth performed under strict antiseptic precautions, by by section below the orbit, resecting the malar and severe suppuration; and, as they do not very often pro. part of the superior maxillary bones, promised the duce a really valuable increase in the hearing power, patient complete recovery and no recurrence of the I do not think that even total deafness can justify disease.

On returning home, his physician wrote me as above. I replied that I sincerely hoped for favorable outcome, but much doubted it.

About three weeks later, the tumor reappeared, and the patient died at the expiration of three months with probable extension into the cranial cavity. There was headache, paralytic trouble, and great exophthalmus.

The diversity of opinion in this case appears to me as 'being unusual; one of the foremost men in the South pronounced it syphilis, another eminent surgeon of New York pronounced it non-malignant, both after careful examination, yet the patient succumbed promptly to what was evidently cancerous disease. DISCUSSION.

Dr. D. Braden KYLE, Philadelphia--In regard to microscopic examinations as mentioned in Dr. Shorter's case, I find that it is not always possible to make a diagnosis from the tissue sent for examination, but if certain rules are followed the examination is of value. In a microscopic examination we must take into consideration the fibrous stroma, the blood vessel, and the cells, and their relations to each other. In the case reported I would like to know whether there was any ulceration of the tumor. In the mucous membranes, especially of the upper air passages in which there is very little connecting tissue element and where it lines a bony cavity, the small round cell (embryonic) of inflammation would resemble a sarcoma very much and if there was ulceration you would find the vessels beneath mere sluice-ways and lacking vessel walls, nothing more than an attempt at organization of the embryonic tissue, and not necessarily malignant, although resembling sarcoma. Such an eminent authority as J. Bland Sutton states that it is impossible to differentiate this condition from sarcoma. As carcinoma spreads by the lymphatics, has distinct and well outlined vessel walls, I do not understand how the mistake in diagnosis could be made.

\title{
SOME OBSERVATIONS MADE DURING THE TREATMENT OF CHRONIC CATARRHAL DEAFNESS.
}

Read in the Section on Laryngology and Otology, at the Forty-seveutb Anuual Meting of the American Medical Association, held at Atlanta, Ga., May 5-8. 1896.

BY THOS. H. SHASTID, A.B., M.D. GALESBURG, ILL.

The treatment of chronic catarrhal deafness may be consilered under three heads: Treatment of the ear directly, attention to the throat and nose, attention to conditions of the body in general.

As regards treatment of the ear d speak only of intra-tympanic operations. I we to not, out of the confusion that seems to 列 propriety of the application of these procedures, I ments mounted according to Dr. Barclay's idea the have divided them for the purposes of my own prac- handle is joined to the operating shaft by a lateral shaft tice into two well-defined classes. Into the first of in such manner that the axis of the handle, prolonged these I have placed such procedures as; while of forward, intersects the axis of the operating shaft 
exactly at the operative extremity. I have had several instruments mounted in this manner, and find that it gives a precision and lightness of touch unattainable by any other means. I believe that Dr. Barclay's idea constitutes a real progress in otology.

Apropos of the effect upon the hearing of nasal and pharyngeal treatment, I urge the importance to the hearing, of vibration or massage of the nasal and pharyngeal mucous membranes when these structures are the seat of atrophy. The loss of hearing accompanying this throat and nose condition is not invariably slight, though it is usually asserted to be so, being in some cases great enough to interfere seriously with ordinary conversation. I believe that in these cases massage of the nose and throat mucous membrane, if persisted in for some time, will result in relieving a large proportion of them of a measure of their embarrassment. Such has been my experience, and $I$ think that I have exercised reasonable care in the exclusion of other possible causes for the improvement. The only instrument that I have used has been Dr. Freudenthal's vibrator. I have seldom seen any improvement until the massage has been continued for a long time.

Under the head of attention to conditions of the body in general, I report a case in which the hearing was very powerfully affected by belladonna. A patient whom I was treating for chronic catarrhal deafness would, at irregular intervals. suffer a very considerable aggravation of his trouble. This would in a few days quite, or nearly, disappear, only to return in a few days more. The exacerbations were not accompanied by symptoms of cold, but by unusual dryness of the mucous membrane of the throat and nose. On inquiry $I$ found that the patient was occasionally taking a purgative pill which contained, among other ingredients, a quarter of a grain of the extract of belladonna. Naturally associating the belladonna with the dryness, I directed the patient to observe whether or not his periods of increased deafness followed the use of the pill. He reported that they really followed its use. Then, in order to eliminate as possible sources of error the influence of suggestion and also of the various drugs which the pill contained other than the belladonna, I ordered a discontinuance of the pill and then each time the patient came to me I administered to him a tablet, sometimes a blank one, sometimes one containing a quarter of a grain of the extract of belladonna. Each time the tablet containing the balladonna was administered the patient suffered this aggravation, but at no time did he experience an increase in deafness after the administration of the blank tablet. It would seem that the deafening effect of the drug was exerted chiefly upon the middle ear; for the patient's ordinarily somewhat increased cranial perception was still further increased whenever he took the belladonna. I thought the increased difficulty in hearing arose from impairment of sound conduction due to inspissation of secretion among the tympanic folds and the ossicles.

Roentgen Ray Locates Bullet Through the Skull.-- The last Deutsche med. Woch. (August 13) brings us actual photographs of the heads of a couple of Eulenburg's patients, in which the Roentgen ray discloses and locates a bullet inside the skull. The photograph was taken with the head of the patient resting on the plate holder, with the Crookes' tube about 24 c. above.
SOME RELATIONS OF CRIME TO INSANITY AND STATES OF MENTAL ENFEEBLEMENT.

Read in the Section on Neprology and Medical Jurisprudence at the Forty-seventh Annual Meeting of the American Medical Asso chation, beld at Atlant a,Ga., May 5-8. 1890 .

BY H. E. ALLISON, M.D.

MEDICAL SUPERINTENDENT MATTEA WAN STATE HOSPITAL,

Any study of penology should consider not only crime and its punishment, but should also investigate the mental and physical state of the criminal. his capacity and his needs. There are conditions both of body and mind either congenital or acquired which render a person dangerous to himself and others, and attempts to repress criminal acts and to protect society from their consequences and their repetition can never be in any great degree successful until we look in part to the individual and examine him as to his status as a man. With this end in view and especially in the case of the young, who are first offenders, the courts should place criminals in secure custody where they should be confined upon indeterminate sentences and undergo careful observation and training at the hands of men capable of judging just what corrective or remedial measures are needed and for what length of time the convict should be deprived of his liberty.

The anthropologic study of the criminal has of late years interested scholars and especially medical men, and there has been much written and much active discussion as to the relations the criminal bears to himself and to society. As medical men we are interested in the criminal himself; and not so much in the nature and character of crime and its punishment, except as incidentally it involves the study of the man. A great deal of stress has been laid upon marks of degeneracy in the criminal and while we admit the existence of many physical anomalies and mental obliquities among the inmates of our penal institutions we can not point to any one feature or group of peculiarities that necessarily stamps the subject as certainly belonging to the criminal class. To a large degree, however, these factors are useful to enable us to judge something of the probabilities which attach to a person's pursuing a criminal career and aid us in adopting reformatory methods, educational, disciplinary and therapeutic, by which we may combat and change inherent or acquired conditions. We can realize that a child with an excellent heredity and a healthy body and mind is more insured aguinst a. criminal career than one presenting all the stigmata of degenerncy. Society has greater natural safeguards in the one than in the other.

The two great determining influences for good or evil are heredity and environment. The medical aspect of crime is more concerned with the former, although the latter can not be disassociated from the question. Environment being susceptible to educational influences and removable, either in a degree or entirely, is more related to the province of the sociologist. It is probable that to environment must be credited the greater number of criminal acts, as the early teaching and training of the child influences largely his subsequent career. Hereditary defects follow closely as a causative factor in the genesis of crime. Out of 6,151 admissions to the Elmira Reformatory, insanity and epilepsy in progenitors were clearly present in 11 per cent. of the number and to this should be added a proportion, uncertain in quantity, wherein ances- 